\title{
Prevention of ischemia-reperfusion injury in cardiac surgery: Therapeutic strategies targeting signaling pathways
}

\author{
Kay Maeda, MD, PhD, and Marc Ruel, MD, MPH, FRCSC
}

See related article on pages 902-9.

Ischemia-reperfusion (IR) injury is known as the tissue damage that results from the process of ischemia followed by the further insult induced by the restoration of blood supply to ischemic tissues. Reperfusion causes an inflammatory response as a result of the induction of various cytokines and chemokines and increased oxidative stress, which lead to microvascular dysfunction in the ischemic tissues and organs. Lung IR injury is one of the main causes of reperfusion pulmonary edema, acute respiratory distress syndrome, and respiratory failure after surgery with cardiopulmonary bypass.

Even though there have been reports proposing various organ protection strategies for IR injury, no effective prophylaxis and treatment have yet been found. During the last decade, several studies have gradually elucidated the detailed molecular mechanism of IR injury, as summarized in Figure 1. As one can discern, various inflammatory signaling pathways are complexly intertwined, such as free radical-mediated cell damage, inflammatory cell infiltrates with the generation of reactive oxygen species, production of cytokines and chemokines, complement activation, and changes in endothelial nitric oxide synthase (eNOS) and induced nitric oxide synthase activity. Therapeutic strategies targeting these signaling pathways have been suggested in both in vitro and in vivo experiments. For example, a recent article by Chouchani and colleagues ${ }^{1}$ revealed a novel pathway for metabolic control of mitochondrial reactive oxygen species production and showed that inhibition of ischemic succinate accumulation and its oxidation is a potential therapeutic target to decrease IR injury.

The research reported in this issue of the Journal by Matsuo and colleagues ${ }^{2}$ took notice of the pleiotropic effects of statins. The rationale was that statins may exert potential beneficial effects on IR injury by improving endothelial function, decreasing oxidative stress and the inflammatory

From the Division of Cardiac Surgery, University of Ottawa Heart Institute, Ottawa, Ontario, Canada.

Disclosures: Authors have nothing to disclose with regard to commercial support.

Received for publication Nov 25, 2014; accepted for publication Nov 25, 2014; available ahead of print Dec 20, 2014

Address for reprints: Marc Ruel, MD, MPH, FRCSC, Division of Cardiac Surgery, University of Ottawa Heart Institute, 40 Ruskin St, Suite 3402, Ottawa, ON,

Canada (E-mail: mruel@ottawaheart.ca).

J Thorac Cardiovasc Surg 2015;149:910-1

$0022-5223 / \$ 36.00$

Copyright (c) 2015 by The American Association for Thoracic Surgery

http://dx.doi.org/10.1016/j.jtcvs.2014.11.067 response, and inhibiting thrombogenic activation. In in vivo experiments, the IR injury preventive effect of statins has already been reported in various organs, such as the heart, lungs, spinal cord, and intestine. ${ }^{3-6}$ The article by Matsuo and colleagues, ${ }^{2}$ however is the first to report a preventive effect of rosuvastatin calcium (INN rosuvastatin) against IR injury in lungs with pulmonary hypertension $(\mathrm{PH})$ with severe baseline endothelial cell remodeling and dysfunction. Interestingly, single-dose rosuvastatin contributed to a significant reduction in lung edema and amelioration of lung oxygenation through eNOS upregulation and the prevention of macrophage infiltration in lungs with $\mathrm{PH}$.

Previously, Murata and colleagues ${ }^{6}$ have reported that in rat lungs with hypoxia-induced PH fluvastatin sodium (INN fluvastatin) treatments prevented the hypoxia-induced tight coupling of caveolin-1 with eNOS, the dissociation of heat shock protein 90 from eNOS, and the decrease in eNOS serine 1177 phosphorylation, which is an index of eNOS activation. Taken together with this study by Matsuo and colleagues, ${ }^{2}$ these results suggest that statins could be a potential therapeutic agent for the treatment of $\mathrm{PH}$ through protection of the eNOS-nitric oxide pathway against hypoxia-induced endothelial dysfunction.

From a clinical application point of view, however, it must be noted that the dose of rosuvastatin used in the study of Matsuo and colleagues ${ }^{2}$ was approximately 10 -fold the clinical dose. Furthermore, some clinical trials have revealed that statin therapy has no beneficial effect on patients with $\mathrm{PH}^{7,8}$ Another recent article indicated that a clinical dose of $20 \mathrm{mg} / \mathrm{d}$ exerted a enhancing effect on small guanosine triphosphate-binding protein guanosine diphosphate dissociation stimulator expression, with resultant Ras-related C3 botulinum toxin substrate degradation through the phosphoinositide 3-kinase/protein kinase B pathway and reduced oxidative stress in endothelial cells. ${ }^{9}$ Further study is necessary to evaluate the effects, if any, of clinical doses of statins and the appropriate timing of their administration to achieve protective effects against IR injury.

The disagreement in effects seen between in vivo experiments and clinical trials implies the possibility that the action mechanism of statin against PH in human beings may be different than that in nonhuman animals; however, many pleiotropic effects of statins are evident in both nonhuman animals and human beings. From other past reports, it is conceivable that statins also affect various points of multiple cascades that are co-stimulated during inflammatory response. Matsuo and colleagues ${ }^{2}$ did not explore 


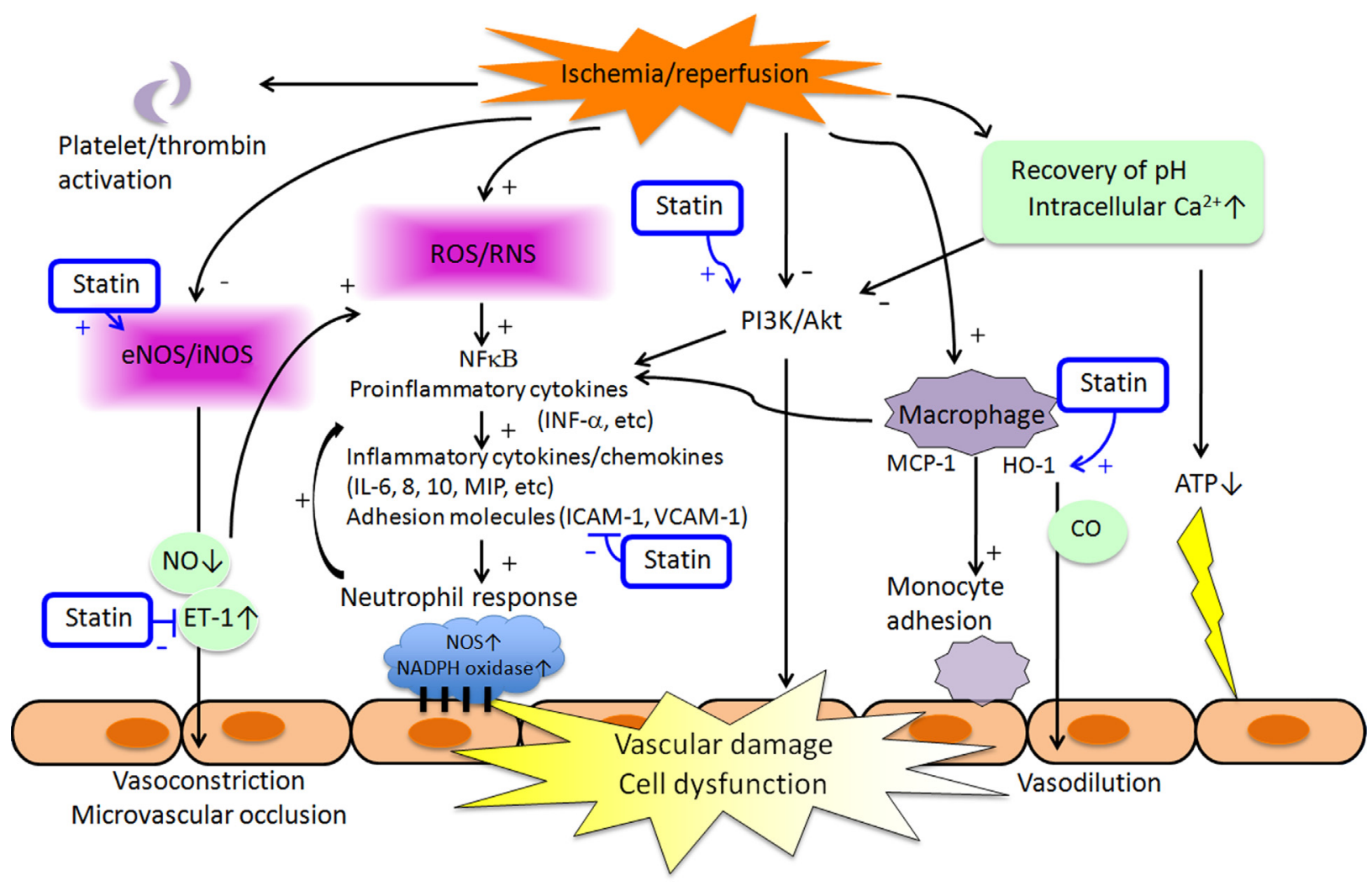

FIGURE 1. Mechanisms involved in ischemia-reperfusion injury and targeting pathways of statins. $\mathrm{Ca}^{2+}$, Calcium ion; $R O S$, reactive oxygen species; $R N S$, reactive nitrogen species; $P I 3 K$, phosphoinositide 3-kinase; $A k t$, protein kinase $\mathrm{B}$; $e N O S$, endothelial nitric oxide synthase; iNOS, induced nitric oxide synthase; $N F \kappa B$, nuclear factor $\kappa \mathrm{B} ; I N F$, interferon; $M C P$, monocyte chemotactic protein; $H O$, heme oxygenase; $I L$, interleukin; $M I P$, macrophage inflammatory proteins; $A T P$, adenosine triphosphate; ICAM, intracellular cell adhesion molecule; VCAM, vascular cell adhesion molecule; $C O$, carbon monoxide; $N O$, nitric oxide; $E T$, endothelin; $N O S$, nitric oxide synthase; $N A D P H$, nicotinamide adenine dinucleotide phosphate (reduced form).

the other adhesion molecules and cytokines and chemokines being secreted in the lung after IR, and thus further study is required to elucidate other potential protective mechanisms that statins confer against IR injury to lungs with $\mathrm{PH}$, with the aim of finally achieving a positive clinical impact for our patients with $\mathrm{PH}$.

\section{References}

1. Chouchani ET, Pell VR, Gaude E, Aksentijević D, Sundier SY, Robb EL, et al. Ischaemic accumulation of succinate controls reperfusion injury through mitochondrial ROS. Nature. 2014;515:431-5.

2. Matsuo S, Saiki Y, Adachi O, Kawamoto S, Fukushige S, Horii A, et al. Singledose rosuvastatin ameliorates lung ischemia-reperfusion injury via upregulation of endothelial nitric oxide synthase and inhibition of macrophage infiltration in rats with pulmonary hypertension. J Thorac Cardiovasc Surg. 2015;149:902-9.

3. Di Napoli P, Taccardi AA, Grilli A, De Lutiis MA, Barsotti A, Felaco M, et al. Chronic treatment with rosuvastatin modulates nitric oxide synthase expression and reduces ischemia-reperfusion injury in rat hearts. Cardiovasc Res. 2005;66: 462-71.
4. Die J, Wang K, Fan L, Jiang Y, Shi Z. Rosuvastatin preconditioning provides neuroprotection against spinal cord ischemia in rats through modulating nitric oxide synthase expressions. Brain Res. 2010;1346:251-61.

5. Naito Y, Katada K, Takagi T, Tsuboi H, Kuroda M, Handa O, et al. Rosuvastatin reduces rat intestinal ischemia-reperfusion injury associated with the preservation of endothelial nitric oxide synthase protein. World J Gastroenterol. 2006;12: 2024-30.

6. Murata T, Kinoshita K, Hori M, Kuwahara M, Tsubone H, Karaki H, et al Statin protects endothelial nitric oxide synthase activity in hypoxiainduced pulmonary hypertension. Arterioscler Thromb Vasc Biol. 2005; 25:2335-42.

7. Zeng WJ, Xiong CM, Zhao L, Shan GL, Liu ZH, Xue F, et al. Atorvastatin in Pulmonary Arterial Hypertension (APATH) Study Group. Atorvastatin in pulmonary arterial hypertension (APATH) study. Eur Respir J. 2012;40:67-74.

8. Kawut SM, Bagiella E, Lederer DJ, Shimbo D, Horn EM, Roberts KE, et al; ASA-STAT Study Group. Randomized clinical trial of aspirin and simvastatin for pulmonary arterial hypertension: ASA-STAT. Circulation. 2011;123: 2985-93.

9. Tanaka S, Fukumoto Y, Nochioka K, Minami T, Kudo S, Shiba N, et al. Statins exert the pleiotropic effects through small GTP-binding protein dissociation stimulator upregulation with a resultant Rac1 degradation. Arterioscler Thromb Vasc Biol. 2013;33:1591-600. 